\title{
Factors predicting the need for hemorrhage control intervention in patients with blunt pelvic trauma: a retrospective study
}

\author{
Myoung Jun Kim, Jae Gil Lee and Seung Hwan Lee*
}

\begin{abstract}
Background: Blunt pelvic injuries are often associated with pelvic fractures and injuries to the rectum and genitourinary tract. Pelvic fractures can lead to life-threatening hemorrhage, which is a common cause of morbidity and mortality in trauma. Thus, early identification of patients with pelvic fractures at risk severe bleeding requiring urgent hemorrhage control is crucial. This study aimed to investigate early factors predicting the need for hemorrhage control in blunt pelvic trauma.

Methods: The medical records of 1760 trauma patients were reviewed retrospectively between January 2013 and June 2018. We enrolled 187 patients with pelvic fracture due to blunt trauma who were older than 15 years. The pelvic fracture pattern was classified according to the Orthopedic Trauma Association/Arbeitsgemeinschaft fur Osteosynthesefragen (OTA/AO) classification. A multivariate logistic regression model was used to determine independent predictors of the need for pelvic hemorrhage control intervention.

Results: The most common pelvic fracture pattern was type A (54.5\%), followed by types B (36.9\%) and C (8.6\%). Of 187 patients, 48 (25.7\%) required pelvic hemorrhage control intervention. Hemorrhage control interventions were most frequently performed in patients with type B fractures (54.2\%). Multivariate logistic regression analysis revealed that type $B$ (odds ratio $[O R]=4.024,95 \%$ confidence interval $[C l]=1.666-9.720, p=0.002)$ and $C(O R=7.077$, $95 \% \mathrm{Cl}=1.781-28.129, p=0.005)$ fracture patterns, decreased body temperature $(\mathrm{OR}=2.275,95 \% \mathrm{Cl}=0.134-0.567$, $p<0.001)$, and elevated serum lactate level $(\mathrm{OR}=1.234,95 \% \mathrm{Cl}=1.061-1.435, p=0.006)$ were factors predicting the need for hemorrhage control intervention in patients with blunt pelvic trauma.
\end{abstract}

Conclusion: Patients with type B and C fracture patterns on the OTA/AO classification, hypothermia, or an elevated serum lactate level are at risk for bleeding and require pelvic hemorrhage control intervention.

Keywords: Pelvis, fracture, hemorrhage control

\section{Background}

Pelvic injuries occur frequently, amounting to almost $9 \%$ of all blunt trauma patients [1]. Blunt pelvic injuries from high-energy mechanisms such as a fall from a height or road traffic collision are often associated with pelvic fractures and injuries to the rectum and genitourinary tract $[1-4]$. The seriousness of blunt pelvic fractures lies in the possible occurrence of retroperitoneal

\footnotetext{
* Correspondence: seunghwan@yuhs.ac

Department of Surgery, Yonsei University College of Medicine, 50-1

Yonsei-ro, Seodaemun-gu, Seoul 03722, Republic of Korea
}

hematomas and hemorrhagic shock [5, 6]. Most pelvic hemorrhage occurs from venous and fracture sites (85\%) $[7,8]$. However, in the hemodynamically unstable patient with severe pelvic injury, arterial bleeding is frequent $[4$, 8]. The overall mortality rates of patients with pelvic ring fractures range from $8 \%$ to $13.5 \%$ [1, 9-11]. Pelvic bone fractures with hemodynamic instability are associated with a higher incidence of pelvic vascular injury and hemorrhage, and the mortality rates are reported to be $30 \%-57 \%[10,12,13]$.

(c) The Author(s). 2018 Open Access This article is distributed under the terms of the Creative Commons Attribution 4.0 International License (http://creativecommons.org/licenses/by/4.0/), which permits unrestricted use, distribution, and reproduction in any medium, provided you give appropriate credit to the original author(s) and the source, provide a link to the Creative Commons license, and indicate if changes were made. The Creative Commons Public Domain Dedication waiver (http://creativecommons.org/publicdomain/zero/1.0/) applies to the data made available in this article, unless otherwise stated. 
The recent evolution of rapid pelvic stabilization by external fixation or pelvic binding, and of hemostasis by angiographic embolization, resuscitative endovascular balloon occlusion, or preperitoneal pelvic packing has significantly decreased the mortality rates in devastating pelvic injuries [14-20]. However, early detection of bleeding is not easy in blunt pelvic fractures. Furthermore, in blunt pelvic trauma with hemodynamic instability, it is difficult to achieve adequate hemostasis due to rapid exsanguination.

Therefore, early recognition of bleeding is important because it may increase the success rate of non-surgical treatment, such as angioembolization, and even if surgery is indicated, early surgery has better prognosis. If hemorrhage and coagulopathy progress significantly, no treatment can be expected to produce good clinical outcomes $[18,19,21]$. Thus, the purpose of this study was to investigate early factors predicting the need for hemorrhage control intervention in patients with blunt pelvic trauma.

\section{Methods}

\section{Patient enrollment and data collection}

We conducted a retrospective observational study at a single center in an urban setting in Seoul, South Korea, from January 2013 to June 2018. Of 1760 trauma patients $\geq 15$ years, patients with penetrating injuries $(\mathrm{n}=$ 82 ) were excluded. In patients with blunt trauma ( $\mathrm{n}=$ $1678)$, we also those with no pelvic fractures $(n=1184)$, those who had been managed or evaluated at other hospitals $(\mathrm{n}=252)$, those who died within minutes after arrival in the emergency room $(n=45)$, and/or those who were referred to other hospitals $(n=10)$. Therefore, the study was conducted with a total of 187 patients (Fig. 1). Patients were divided into those who did not undergo hemorrhage control intervention and those who did. Hemorrhage control intervention was defined as angioembolization, external fixation, or preperitoneal pelvic packing.

\section{Clinical variables}

We analyzed the sex, age, injury mechanism, vital signs, Glasgow Coma Scale (GCS) score, current anticoagulant use, Abbreviated Injury Scale (AIS) score, Injury Severity Score (ISS), Revised Trauma Score (RTS), Trauma and Injury Severity Score (TRISS), Acute Physiology and Chronic Health Evaluation (APACHE) II score, and arterial blood values ( $\mathrm{pH}$, base excess, and lactate level). In addition, pelvic radiography of each patient was identified, and patterns of pelvic fracture were classified as types A, B, and C according to the Orthopedic Trauma Association/Arbeitsgemeinschaft fur Osteosynthesefragen (OTA/AO) classification (Table 1). The classification was based on the findings of trauma surgeons and orthopedic surgeons, which were additionally confirmed by surgical and radiological records.

\section{Statistical analysis}

Statistical analysis for investigated items was performed using SPSS $^{\oplus}$ Statistics 23.0 (IBM, Armonk, NY, USA).

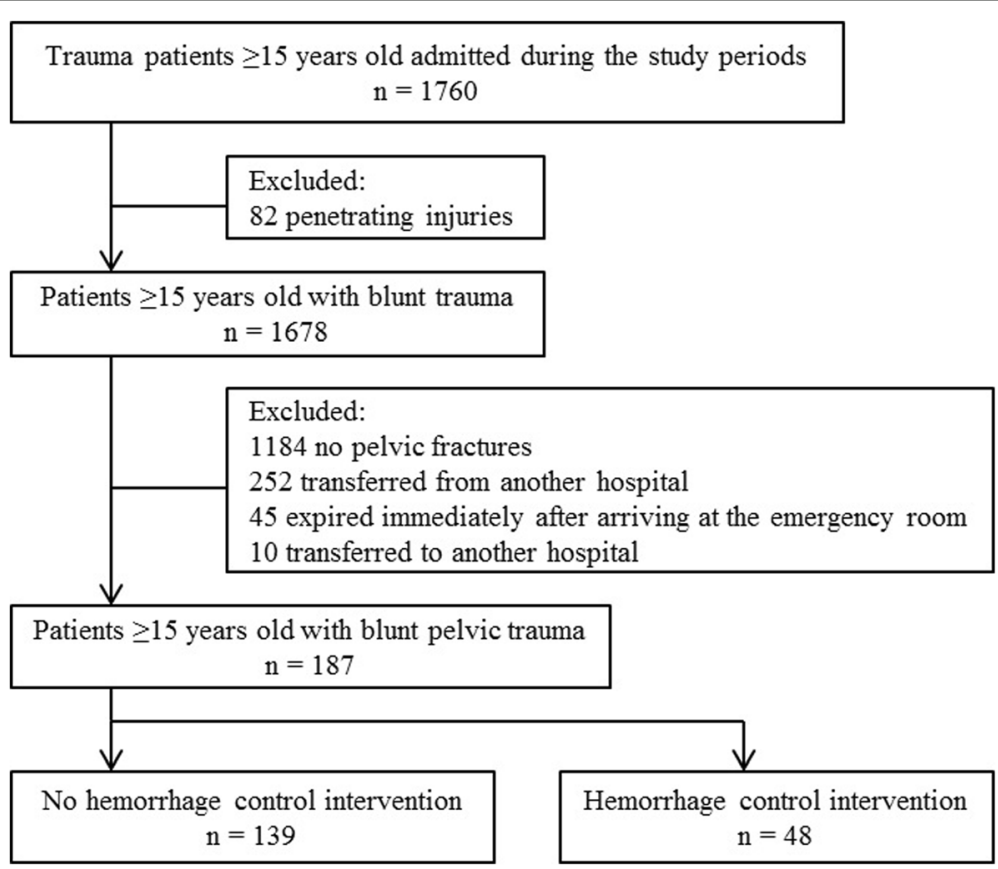

Fig. 1 Flow diagram of patients selected for analysis 
Table 1 OTA/AO classification of pelvic fracture

\begin{tabular}{|c|c|}
\hline Type & Description \\
\hline \multirow[t]{3}{*}{ Type A: Stable - posterior arch is intact } & $\begin{array}{l}\text { A1: Fracture does not involve the pelvic ring (avulsion fracture or fracture of the } \\
\text { iliac wing) } \\
\text { - A1.1: lliac spine } \\
\text { - A1.2: Iliac crest } \\
\text { - A1.3: Ischial tuberosity }\end{array}$ \\
\hline & $\begin{array}{l}\text { A2: Stable or minimally displaced fracture of the pelvic ring } \\
\text { - A2.1: lliac wing fractures } \\
\text { - A2.2: Unilateral fracture of anterior arch } \\
\text { - A2.3: Bifocal fracture of anterior arch }\end{array}$ \\
\hline & $\begin{array}{l}\text { A3: Transverse fracture of the sacrum } \\
\text { - A3.1: Sacrococcygeal dislocation } \\
\text { - A3.2: Sacrum undisplaced } \\
\text { - A3.3: Sacrum displaced }\end{array}$ \\
\hline \multirow[t]{3}{*}{$\begin{array}{l}\text { Type B: Rotationally unstable, vertically stable - incomplete } \\
\text { disruption of the posterior arch }\end{array}$} & $\begin{array}{l}\text { B1: Open book injury (external rotation) } \\
\text { - B1.1: Sacroiliac joint, anterior disruption } \\
\text { - B1.2: Sacral fracture }\end{array}$ \\
\hline & $\begin{array}{l}\text { B2: Lateral compression injury (internal rotation) } \\
\text { - B2.1: Anterior compression fracture, sacrum } \\
\text { - B2.2: Partial sacroiliac joint fracture, subluxation } \\
\text { - B2.3: Incomplete posterior iliac fracture }\end{array}$ \\
\hline & $\begin{array}{l}\text { B3: Bilateral type B fracture } \\
\text { - B3.1: Bilateral open book fracture } \\
\text { - B3.2: Open book fracture and lateral compression } \\
\text { - B3.3: Bilateral lateral compression }\end{array}$ \\
\hline \multirow[t]{3}{*}{$\begin{array}{l}\text { Type C: Rotationally and vertically unstable - complete disruption } \\
\text { of the posterior arch }\end{array}$} & $\begin{array}{l}\text { C1: Unilateral fracture } \\
\text { - C1.1: Fracture of the iliac bone } \\
\text { - C1.2: Sacroiliac dislocation and/or fracture dislocation } \\
\text { - C1.3: Sacral fracture }\end{array}$ \\
\hline & $\begin{array}{l}\text { C2: Bilateral fracture with one side type B fracture (rotationally unstable) and one } \\
\text { side type C fracture (vertically unstable) }\end{array}$ \\
\hline & C3: Bilateral fracture with both sides type C fracture (both sides completely unstable) \\
\hline
\end{tabular}

OTA/AO Orthopedic Trauma Association/Arbeitsgemeinschaft fur Osteosynthesefragen.

Categorical data are presented as numbers (\%), and they were compared using the chi-square or Fisher's exact tests. Continuous variables are expressed as mean \pm standard deviation or medians (the 25th and 75th quantiles), and the data were compared between groups using the Student t-test or Mann-Whitney $U$ test. Factors found to be significantly associated with the need for hemorrhage control intervention on univariate analysis were included in the multivariate analysis. Logistic regression modeling was performed using the maximum likelihood method and backward stepwise selection. Goodness of fit was assessed using the Hosmer-Lemeshow test. The odds ratios (ORs) are given with 95\% confidence intervals (CIs). A $p$ value $<0.05$ was considered statistically significant.

\section{Results}

\section{Patients}

The baseline characteristics of patients are listed in Table 2. Of the 187 patients, 48 underwent hemorrhage control intervention and 139 did not undergo hemorrhage control intervention. The sex ratio was 125:62 (66.8\%:33.2\%, male/female). There was no significant difference between the hemorrhage control and non-hemorrhage control intervention groups $(p=0.290)$. There was no significant difference between the two groups in the use of anticoagulants $(p=0.530)$. When classified according to the injury mechanism, pedestrian trauma injuries caused by motor vehicle accidents were the most frequent in both groups, followed by falls, which had the second highest frequency. However, there was no statistically significant difference between the groups that received hemorrhage control intervention and those that did not $(p=0.497)$.

When the AIS values of the two groups were compared, both systems, such as the abdomen $(p<0.001)$ and the extremity $(p<0.001)$, showed a significant difference. However, there were no significant differences in other systems. Furthermore, there were significant differences in the ISS $(p<0.001)$, RTS $(p=0.004)$, TRISS $(p=0.001)$, and APACHE II score $(p<0.001)$ between the two groups.

\section{Clinical variables comparison}

The vital signs and laboratory variables of patients are shown in Table 3. Systolic blood pressure $(p=0.008)$ and body temperature $(p<0.001)$ in the hemorrhage control intervention group were significantly lower than 
Table 2 Baseline characteristics of patients

\begin{tabular}{|c|c|c|c|}
\hline & $\begin{array}{l}\text { No hemorrhage control } \\
\text { intervention }(n=139)\end{array}$ & $\begin{array}{l}\text { Hemorrhagic control } \\
\text { intervention }(n=48)\end{array}$ & $p$ Value \\
\hline Age (years) & $49.1 \pm 19.9$ & $53.9 \pm 20.5$ & 0.154 \\
\hline Sex & & & 0.290 \\
\hline Male & $96(69.1)$ & $29(60.4)$ & \\
\hline Female & 43 (30.9) & 19 (39.6) & \\
\hline $\begin{array}{l}\text { Anticoagulant } \\
\text { use }\end{array}$ & $8(5.8 \%)$ & $4(8.3 \%)$ & 0.530 \\
\hline $\begin{array}{l}\text { Injury } \\
\text { mechanism }\end{array}$ & & & 0.497 \\
\hline $\begin{array}{l}\text { MVA } \\
\text { (pedestrian) }\end{array}$ & $51(36.7)$ & $23(47.9)$ & \\
\hline $\begin{array}{l}\text { MVA } \\
\text { (passenger) }\end{array}$ & $11(7.9)$ & $2(4.2)$ & \\
\hline $\begin{array}{l}\text { Motorcycle } \\
\text { accidents }\end{array}$ & $23(16.5)$ & $5(10.4)$ & \\
\hline Falls & $51(36.7)$ & 16 (33.3) & \\
\hline Others & $3(2.2)$ & $2(4.2)$ & \\
\hline \multicolumn{4}{|l|}{ AIS } \\
\hline $\begin{array}{l}\text { Head and } \\
\text { neck }\end{array}$ & $1.0(0.0,2.0)$ & $2.0(0.0,3.0)$ & 0.264 \\
\hline Face & $0.0(0.0,1.0)$ & $0.0(0.0,1.0)$ & 0.539 \\
\hline Chest & $0.0(0.0,3.0)$ & $2.0(0.0,3.0)$ & 0.049 \\
\hline Abdomen & $0.0(0.0,2.0)$ & $2.5(0.0,3.0)$ & $<0.001$ \\
\hline Extremities & $2.0(2.0,3.0)$ & $3.5(2.0,4.0)$ & $<0.001$ \\
\hline External & $1.0(1.0,1.0)$ & $1.0(1.0,1.0)$ & 0.754 \\
\hline ISS & $17.4 \pm 11.2$ & $30.1 \pm 13.4$ & $<0.001$ \\
\hline RTS & $7.092 \pm 1.482$ & $6.123 \pm 2.089$ & 0.004 \\
\hline TRISS (\%) & $87.09 \pm 23.07$ & $68.67 \pm 32.13$ & 0.001 \\
\hline APACHE ॥ & $16.1 \pm 8.6$ & $24.6 \pm 10.7$ & $<0.001$ \\
\hline $\begin{array}{l}\text { In-hospital } \\
\text { mortality }\end{array}$ & $9(6.5)$ & 17 (35.4) & $<0.001$ \\
\hline
\end{tabular}

Values are presented as mean \pm SD or $\mathrm{n}(\%)$.

MVA motor vehicle accident, AIS Abbreviated Injury Scale, ISS Injury Severity Score, RTS Revised Trauma Score, TRISS Trauma and Injury Severity Score, APACHE Acute Physiology and Chronic Health Evaluation

those in the non-hemorrhage control intervention group. In the arterial gas analysis, the base excess ( $p=$ 0.001 ) was significantly lower in the hemorrhage control intervention group than those in the non-hemorrhage control intervention group, and lactate $(p<0.001)$ was significantly higher.

\section{Comparison between two groups according to pelvic fracture pattern}

According to the classification of posterior pelvic ring stability based on OTA/AO, type B with partial instability was the most common $(\mathrm{n}=26,54.2 \%)$ in the group with hemorrhage control intervention, followed by types A and C. Type A ( $n=91,65.5 \%)$ was the most common in the non-hemorrhage control intervention group,
Table 3 Comparison of clinical parameters between two groups

\begin{tabular}{clll}
\hline & $\begin{array}{l}\text { No hemorrhage control } \\
\text { intervention }(n=139)\end{array}$ & $\begin{array}{l}\text { Hemorrhagic control } \\
\text { intervention }(n=48)\end{array}$ & $p$ Value \\
\hline $\begin{array}{clll}\text { Vital sign } \\
\text { SBP }\end{array}$ & $118.8 \pm 33.7$ & $98.8 \pm 46.2$ & 0.008 \\
HR & $88.7 \pm 23.3$ & $96.1 \pm 31.1$ & 0.132 \\
RR & $18.7 \pm 4.5$ & $17.3 \pm 7.2$ & 0.223 \\
BT & $36.4 \pm 0.5$ & $35.9 \pm 0.7$ & $<0.001$ \\
GCS & $12.9 \pm 4.0$ & $11.4 \pm 4.8$ & 0.057 \\
ABGA & & & \\
pH & $7.38 \pm 0.08$ & $7.33 \pm 0.16$ & 0.057 \\
BE & $-3.48 \pm 3.30$ & $-6.71 \pm 5.79$ & 0.001 \\
Lactate & $2.99 \pm 1.89$ & $5.42 \pm 4.26$ & $<0.001$
\end{tabular}

Values are presented as mean \pm SD.

$A B G A$ arterial blood gas analysis, $S B P$ systolic blood pressure, $H R$ heart rate, $R R$ respiration rate, $B T$ body temperature, GCS Glasgow Coma Scale, $B E$ base excess

followed by types B and C. Overall, there was significant difference $(p<0.001)$ between the groups with and without hemorrhage control intervention according to the OTA/AO classification (Table 4).

\section{Logistic regression analysis for predictors of hemorrhage control intervention}

The results of the univariate and multivariate regression analysis models are shown in Table 5 . As a result, in the pelvic bone fracture pattern according to OTA/AO classification, types $\mathrm{B}(\mathrm{OR}=4.024,95 \% \mathrm{CI}=1.666-9.720, p$ $=0.002)$ and $\mathrm{C}(\mathrm{OR}=7.077,95 \% \mathrm{CI}=1.781-28.129, p$ $=0.005)$ were identified as predictors of hemorrhage control intervention. Among the clinical parameters, body temperature $(\mathrm{OR}=0.275,95 \% \mathrm{CI}=0.134-0.567, p$ $<0.001)$ and lactate $(\mathrm{OR}=1.234,95 \% \mathrm{CI}=1.061-1.435$, $p=0.006$ ) were identified as predictors. Furthermore, although univariate analysis revealed that the two groups had no significant differences in the use of anticoagulants, we additionally conducted a multivariable logistic regression analysis including "anticoagulant use" as covariate, given its proven clinical significance. There was no difference in the results (Additional file 1).

Table 4 Comparison via pelvic fracture pattern of patients between two groups (OTA/AO)

\begin{tabular}{llll}
\hline & $\begin{array}{l}\text { No hemorrhage control } \\
\text { intervention }(\mathrm{n}=139)\end{array}$ & $\begin{array}{l}\text { Hemorrhagic control } \\
\text { intervention }(\mathrm{n}=48)\end{array}$ & $p$ Value \\
\hline $\begin{array}{llll}\text { Pelvic fracture } \\
\text { pattern }\end{array}$ & & $<0.001$ \\
A & $91(65.5)$ & $11(22.9)$ & \\
B & $43(30.9)$ & $26(54.2)$ & \\
C & $5(3.6)$ & $11(22.9)$ & \\
\hline
\end{tabular}

OTA/AO Orthopedic Trauma Association/Arbeitsgemeinschaft fur Osteosynthesefragen 
Table 5 Multivariable regression analysis according to OTA/AO classification

\begin{tabular}{|c|c|c|c|c|}
\hline \multirow[t]{2}{*}{ Characteristics } & \multicolumn{2}{|l|}{ Univariate analysis } & \multicolumn{2}{|l|}{ Multivariate analysis } \\
\hline & OR $(95 \% \mathrm{Cl})$ & $p$ Value & OR $(95 \% \mathrm{Cl})$ & $p$ Value \\
\hline \multicolumn{5}{|c|}{ Pelvic fracture pattern } \\
\hline A & Ref. & & & \\
\hline B & $5.002(2.264-11.052)$ & $<0.001$ & $4.024(1.666-9.720)$ & 0.002 \\
\hline C & $18.200(5.328-62.166)$ & $<0.001$ & 7.077 (1.781-28.129) & 0.005 \\
\hline SBP & $0.986(0.977-0.995)$ & 0.003 & & \\
\hline BT & $0.205(0.104-0.401)$ & $<0.001$ & $0.275(0.134-0.567)$ & $<0.001$ \\
\hline Base excess & $0.847(0.780-0.920)$ & $<0.001$ & & \\
\hline Lactate & $1.336(1.162-1.536)$ & $<0.001$ & $1.234(1.061-1.435)$ & 0.006 \\
\hline
\end{tabular}

SBP systolic blood pressure, $B T$ body temperature, OR odds ratio, $C l$ confidence interval, OTA/AO Orthopedic Trauma Association/Arbeitsgemeinschaft fur Osteosynthesefragen

\section{Discussion}

Blunt pelvic injuries from high-energy mechanisms are often associated with pelvic fractures and injuries to the rectum and genitourinary tract [1-4]. The seriousness of blunt pelvic fractures lies in the possible occurrence of retroperitoneal hematomas and hemorrhagic shock [5, 6]. Unstable pelvic fractures are associated with massive hemorrhage [22], which is the leading cause of death in patients with major pelvic fractures [23, 24]. In the present study, patients with pelvic bleeding had significantly higher in-hospital mortality rates than those without pelvic bleeding. Moreover, among patients with pelvic bone fractures, trauma-related severity scores such as the GCS, ISS, RTS, and TRISS were significantly higher in the hemorrhage control intervention group than in the non-hemorrhage control intervention group. Therefore, trauma patients in need of emergent intervention or surgery for ongoing hemorrhage have increased chances of survival if the elapsed time between traumatic injury and bleeding control intervention is minimized [5, 10, 16, 25].

The recent evolution of rapid pelvic stabilization by external fixation or pelvic binding and of hemostasis by angiographic embolization, resuscitative endovascular balloon occlusion, or preperitoneal pelvic packing has significantly decreased the mortality rates of devastating pelvic injuries. However, early detection of bleeding is not easy in blunt pelvic fractures [14-20]. Furthermore, despite ongoing bleeding in a severely injured patient arriving at a hospital, the vital signs of the patient may not show typical changes in the immediate and early periods after injury $[26,27]$. In blunt pelvic trauma with hemodynamic instability, it is difficult to achieve adequate hemostasis due to rapid exsanguination. Therefore, early and quick prediction of the need for hemorrhage control interventions for pelvic injuries is important.

In the present study, type $\mathrm{B}$ and $\mathrm{C}$ fractures according to the OTA/AO classification were revealed as independent factors predicting the need for hemorrhage control intervention in patients with blunt pelvic trauma. Type $B$ and $C$ fractures show pelvic bone fracture patterns including posterior pelvic ring instability. Type $B$ fracture is a result of rotational forces that cause partial disruption of the posterior sacroiliac complex [28, 29]. Complete disruption of the posterior complex occurs in type $\mathrm{C}$ fractures, which are both rotationally and vertically unstable $[28,29]$. In this study, the need for early hemorrhage control interventions was 4 and 7 times higher for type $\mathrm{B}$ and $\mathrm{C}$ fractures than for type $\mathrm{A}$ fractures, respectively.

Although patients with high-grade pelvic ring injuries may not have significant bleeding, the bleeding risk generally increases with the degree of instability of the posterior pelvic ring [30, 31]. Manson et al. [24] reported that transfusion requirements and mortality were significantly higher in the posterior ring instability pattern than in the pelvic bone fracture pattern without involvement of the posterior structures, and this suggests that stretching and tearing of soft tissues, like artery and vein, around the posterior pelvic ring showed greater hemorrhagic instability in lateral compression III, anterior-posterior compression III, and vertical shear. Costantini et al. [32] similarly concluded that there is a higher need for hemorrhage control intervention in the posterior pelvic ring instability patterns, such as anterior-posterior compression III or open pelvic fracture. In the current guidelines, markers of pelvic hemorrhage also include anterior-posterior and vertical shear deformations on standard roentgenograms [33-35].

In the present study, patterns of pelvic fracture were evaluated with pelvic radiography. To date, CT has replaced radiography in classifying pelvic fractures [35]. Contrast-enhanced $\mathrm{CT}$ also helps diagnose pelvic hematoma and active extravasation of contrast [7]. Multidetector CT has short acquisition times and allows for rapid identification and assessment of pelvic hemorrhage [36]. However, CT cannot be performed for all patients and is dependent on the situation, such as hemodynamic instability or absence of resources in each institution [36]. 
Although evaluation of the sacrum and sacroiliac joints is sometimes limited on a portable anteroposterior pelvic radiograph, pelvic radiography is one of the tools that can easily and quickly reveal the pelvic bone fracture pattern, and it is generally performed as an initial examination in the trauma bay [37, 38]. Furthermore, pelvic radiography in hemodynamically unstable patients helps in identifying life-threatening pelvic ring injuries [39].

The patterns of pelvic fracture were classified as types $\mathrm{A}, \mathrm{B}$, and $\mathrm{C}$ using the OTA/AO classification. The OTA/ AO classification was based on fracture stability, especially the stability of the posterior lesion [28, 40-42]. Unstable pelvic fractures are more frequently associated with hemorrhage $[4,8]$. The OTA/TA classification is easier to use in classifying patterns of pelvic fracture through pelvic radiography than the Young-Burgess classification, which is based on mechanism of injury [38, 42]. Furthermore, the Young-Burgess classification scheme for pelvic ring injury basically cannot be used to guide transfusion requirements and the need for angiography and embolization in individual cases [30].

In the multivariable regression analysis, the body temperature was significantly low in the hemorrhage control intervention group. In other words, hypothermia was a predictor of the need for hemorrhage control intervention. Hypothermia is common in trauma victims and is associated with an increased risk of severe bleeding and increased mortality [43, 44]. In the study of Gentilello et al. [45], the group of trauma patients with a mean body temperature of $34.5^{\circ} \mathrm{C}$ showed a mortality of $100 \%$ when they failed to be rewarmed to $36^{\circ} \mathrm{C}$. Therefore, warming and euthermia in a trauma patient with pelvic bone fracture are crucial.

The current guidelines recommend either serum lactate or base deficit measurements as sensitive tests to estimate and monitor the extent of bleeding and shock [46-49]. Additionally, serial measurement of these parameters can be used to monitor the response to therapy [48]. The amount of lactate produced by anaerobic glycolysis is an indirect marker of oxygen debt, tissue hypoperfusion, and severity of hemorrhagic shock $[47,50]$. Similarly, base deficit values derived from arterial blood gas analysis provide an indirect estimation of global tissue acidosis due to impaired perfusion $[50,51]$. Moreover, the lactate and base deficit have been mentioned in many studies as predictive values related to bleeding in pelvic bone fractures in trauma patients [52-55]. In this study, serum lactate was identified as an independent predictor of the need for hemorrhage control intervention. In other previous studies, both initial serum lactate and lactate clearance after 6 hours were identified as independent risk factors for mortality in trauma patients [56]. In addition, an increased serum lactate level is associated with massive hemorrhage in pelvic ring fractures [57], and the serum lactate level measured in the pre-hospital period was found to be associated with the clinical outcome in trauma patients [58].

We additionally conducted a multivariable logistic regression analysis including "anticoagulant use" as potential predictor. It is indisputable that anticoagulants may worsen bleeding in a trauma patient. However, despite the clinical significance of anticoagulants, the results have not changed whether anticoagulant use is included or not in the multivariable logistic regression analysis. Therefore, our results should be carefully interpreted and used strictly in a wider context of the patient's clinical condition, clinical setting, and individual included factors.

There are several limitations to the present study. First, it is a retrospective study. Second, it may be difficult to generalize the results of this study, as it is a single-center study. Third, the statistical power is insufficient because of the small number of subjects. Therefore, multicenter studies are needed to overcome these limitations.

\section{Conclusion}

OTA/AO type B and C fractures, hypothermia, and increased lactate level are independent factors predicting the need for hemorrhage control intervention in patients with blunt pelvic traumas. Type $B$ and $C$ fractures are more likely to be associated with vascular injuries than are type A fractures. Hypothermia is well known to worsen coagulopathy. Lactate is a marker of systemic tissue perfusion and is elevated in cases of hypoperfusion of the tissues, such as hemorrhagic shock. These three factors may reflect the severity and occurrence of pelvic bleeding in patients with blunt pelvic trauma. Therefore, the predictors can be helpful in making decisions about management of pelvic bone fractures with hemorrhage.

\section{Additional file}

Additional file 1: Multivariable regression analysis according to OTA/AO classification. (DOCX 14 kb)

\section{Abbreviations \\ AIS: Abbreviated Injury Scale; APACHE: Acute Physiology and Chronic Health Evaluation; BE: Base excess; BT: Body temperature; GCS: Glasgow Coma Scale; HR: Heart rate; ISS: Injury Severity Score; LOS: Length of stay; MV: Mechanical ventilation; MVA: Motor vehicle accident; RR: Respiration rate; RTS: Revised Trauma Score; SBP: Systolic blood pressure; TRISS: Trauma and Injury Severity Score Injury Severity Score}

\section{Acknowledgments}

The authors thank JE Moon for providing assistance with the statistical analyses, and we also thank all of the coordinators for their valuable help and cooperation. 


\section{Availability of data and materials}

The datasets used and/or analyzed during the current study are available from the corresponding author on reasonable request.

\section{Authors' contributions}

SHL designed the study. MJK and SHL were responsible for data acquisition. SHL and MJK analyzed and interpreted the data with JGL. MJK wrote the article. All authors read and approved the final manuscript.

\section{Ethics approval and consent to participate}

The study was approved by the Institutional Review Board of Severance Hospital, Yonsei University Health System (4-2017-0545), which waived the requirement for informed consent because of the retrospective nature of the study.

\section{Consent for publication}

Not applicable.

\section{Competing interests}

The authors declare that they have no competing interests.

\section{Publisher's Note}

Springer Nature remains neutral with regard to jurisdictional claims in published maps and institutional affiliations.

Received: 7 August 2018 Accepted: 5 November 2018 Published online: 16 November 2018

\section{References}

1. Demetriades D, Karaiskakis M, Toutouzas K, Alo K, Velmahos G, Chan L. Pelvic fractures. epidemiology and predictors of associated abdominal injuries and outcomes. J Am Coll Surg. 2002;195:1-10.

2. Snyder HS. Blunt pelvic trauma. Am J Emerg Med. 1988;6:618-27.

3. Trunkey DD, Chapman MW, Lim RC Jr, Dunphy JE. Management of pelvic fractures in blunt trauma injury. J Trauma. 1974:14:912-23.

4. Durkin A, Sagi HC, Durham R, Flint L. Contemporary management of pelvic fractures. Am J Surg. 2006;192:211-23.

5. Heetveld MJ, Harris I, Schlaphoff G, Sugrue M. Guidelines for the management of haemodynamically unstable pelvic fracture patients. ANZ J Surg. 2004;74:520-9.

6. Geeraerts T, Chhor V, Cheisson G, Martin L, Bessoud B, Ozanne A, et al. Clinical review. initial management of blunt pelvic trauma patients with haemodynamic instability. Crit Care. 2007;11:204.

7. Huittinen VM, Slatis P. Postmortem angiography and dissection of the hypogastric artery in pelvic fractures. Surgery. 1973;73:454-62.

8. White CE, Hsu JR, Holcomb JB. Haemodynamically unstable pelvic fractures. Injury. 2009;40:1023-30.

9. Sathy AK, Starr AJ, Smith WR, Elliott A, Agudelo J, Reinert CM, et al. The effect of pelvic fracture on mortality after trauma: an analysis of 63,000 trauma patients. J Bone Joint Surg Am. 2009:91:2803-10.

10. Costantini TW, Coimbra R, Holcomb JB, Podbielski JM, Catalano R, Blackburn $A$, et al. Current management of hemorrhage from severe pelvic fractures. Results of an American Association for the Surgery of Trauma multiinstitutional trial. J Trauma Acute Care Surg. 2016:80:717-23 discussion 723-15.

11. Chu CH, Tennakoon L, Maggio PM, Weiser TG, Spain DA, Staudenmayer KL. Trends in the management of pelvic fractures, 2008-2010. J Surg Res. 2016; 202:335-40.

12. Chiara O, di Fratta E, Mariani A, Michaela B, Prestini L, Sammartano F, et al. Efficacy of extra-peritoneal pelvic packing in hemodynamically unstable pelvic fractures, a propensity score analysis. World J Emerg Surg. 2016;11:22.

13. Starr AJ, Griffin DR, Reinert CM, Frawley WH, Walker J, Whitlock SN, et al. Pelvic ring disruptions: prediction of associated injuries, transfusion requirement, pelvic arteriography, complications, and mortality. J Orthop Trauma. 2002;16:553-61.

14. Burlew CC, Moore EE, Smith WR, Johnson JL, Biffl WL, Barnett CC, et al Preperitoneal pelvic packing/external fixation with secondary angioembolization: optimal care for life-threatening hemorrhage from unstable pelvic fractures. J Am Coll Surg. 2011;212:628-35 discussion 635-7.

15. Tang J, Shi Z, Hu J, Wu H, Yang C, Le G, et al. Optimal sequence of surgical procedures for hemodynamically unstable patients with pelvic fracture. A network meta-analysis. Am J Emerg Med. 2018;S0735-6757(18):30489-3.
16. Matsushima K, Piccinini A, Schellenberg M, Cheng V, Heindel P, Strumwasser $A$, et al. Effect of door-to-angioembolization time on mortality in pelvic fracture. Every hour of delay counts. J Trauma Acute Care Surg. 2018;84: $685-92$

17. Fu CY, Chan SY, Wang SY, Hsieh CH, Liao CH, Huang JF, et al. The effect of angioembolization for life-threatening retroperitoneal hemorrhage in patients with pelvic fracture. Am J Emerg Med. 2018;S0735-6757(18): 30507-2.

18. Tesoriero RB, Bruns BR, Narayan M, Dubose J, Guliani SS, Brenner ML, et al. Angiographic embolization for hemorrhage following pelvic fracture. Is it "time" for a paradigm shift? J Trauma Acute Care Surg. 2017;82:18-26.

19. Burlew CC, Moore EE, Stahel PF, Geddes AE, Wagenaar AE, Pieracci FM, et al. Preperitoneal pelvic packing reduces mortality in patients with lifethreatening hemorrhage due to unstable pelvic fractures. J Trauma Acute Care Surg. 2017:82:233-42

20. Marzi I, Lustenberger T. Management of bleeding pelvic fractures. Scand J Surg. 2014;103:104-11.

21. Balogh Z, Caldwell E, Heetveld M, D'Amours S, Schlaphoff G, Harris I, et al. Institutional practice guidelines on management of pelvic fracture-related hemodynamic instability: do they make a difference? J Trauma. 2005;58: 778-82.

22. Ertel W, Keel M, Eid K, Platz A, Trentz O. Control of severe hemorrhage using C-clamp and pelvic packing in multiply injured patients with pelvic ring disruption. J Orthop Trauma. 2001;15:468-74.

23. Smith W, Williams A, Agudelo J, Shannon M, Morgan S, Stahel P, et al. Early predictors of mortality in hemodynamically unstable pelvis fractures. $J$ Orthop Trauma. 2007;21:31-7.

24. Manson T, O'Toole RV, Whitney A, Duggan B, Sciadini M, Nascone J. YoungBurgess classification of pelvic ring fractures: does it predict mortality, transfusion requirements, and non-orthopaedic injuries? J Orthop Trauma. 2010;24:603-9.

25. Salim A, Teixeira PG, DuBose J, Ottochian M, Inaba K, Margulies DR, et al. Predictors of positive angiography in pelvic fractures: a prospective study. J Am Coll Surg. 2008;207:656-62.

26. Frank M, Schmucker U, Stengel D, Fischer L, Lange J, Grossjohann R, et al. Proper estimation of blood loss on scene of trauma: tool or tale? J Trauma. 2010;69:1191-5

27. Guly HR, Bouamra O, Spiers M, Dark P, Coats T, Lecky FE, Trauma Audit and Research Network. Vital signs and estimated blood loss in patients with major trauma: testing the validity of the ATLS classification of hypovolaemic shock. Resuscitation. 2011:82:556-9.

28. Osterhoff G, Scheyerer MJ, Fritz Y, Bouaicha S, Wanner GA, Simmen HP, et al. Comparing the predictive value of the pelvic ring injury classification systems by Tile and by Young and Burgess. Injury. 2014;45:742-7.

29. Nuchtern JV, Hartel MJ, Henes FO, Groth M, Jauch SY, Haegele J, et al. Significance of clinical examination, CT and MRI scan in the diagnosis of posterior pelvic ring fractures. Injury. 2015:46:315-9.

30. Sarin EL, Moore JB, Moore EE, Shannon MR, Ray CE, Morgan SJ, et al. Pelvic fracture pattern does not always predict the need for urgent embolization. J Trauma. 2005;58:973-7

31. Kimbrell BJ, Velmahos GC, Chan LS, Demetriades D. Angiographic embolization for pelvic fractures in older patients. Arch Surg. 2004;139:72832 discussion 732-3.

32. Costantini TW, Coimbra R, Holcomb JB, Podbielski JM, Catalano RD, Blackburn A, et al. Pelvic fracture pattern predicts the need for hemorrhage control intervention - results of an AAST multi-institutional study. J Trauma Acute Care Surg. 2017;82:1030-8.

33. Miller PR, Moore PS, Mansell E, Meredith JW, Chang MC. External fixation or arteriogram in bleeding pelvic fracture: initial therapy guided by markers of arterial hemorrhage. J Trauma. 2003:54:437-43.

34. Hagiwara A, Minakawa K, Fukushima H, Murata A, Masuda H, Shimazaki S. Predictors of death in patients with life-threatening pelvic hemorrhage after successful transcatheter arterial embolization. J Trauma. 2003;55:696-703.

35. Coccolini F, Stahel PF, Montori G, Biffl W, Horer TM, Catena F, et al. Pelvic trauma: WSES classification and guidelines. World J Emerg Surg. 2017;12:5.

36. Kos S, Gutzeit A, Hoppe H, Liu DM, Jacob AL. Diagnosis and therapy of acute hemorrhage in patients with pelvic fractures. Semin Musculoskelet Radiol. 2013:17:396-406

37. Burgess AR, Eastridge BJ, Young JW, Ellison TS, Ellison PS Jr, et al. Pelvic ring disruptions: effective classification system and treatment protocols. J Trauma. 1990;30:848-56. 
38. Dalal SA, Burgess AR, Siegel JH, Young JW, Brumback RJ, Poka A, et al. Pelvic fracture in multiple trauma: classification by mechanism is key to pattern of organ injury, resuscitative requirements, and outcome. J Trauma. 1989;29: 981-1000 discussion 1000-2.

39. Agri F, Bourgeat M, Becce F, Moerenhout K, Pasquier M, Borens O, et al. Association of pelvic fracture patterns, pelvic binder use and arterial angioembolization with transfusion requirements and mortality rates; a 7-year retrospective cohort study. BMC Surg. 2017;17:104.

40. Furey AJ, O'Toole RV, Nascone JW, Sciadini MF, Copeland CE, Turen C. Classification of pelvic fractures: analysis of inter- and intraobserver variability using the Young-Burgess and Tile classification systems. Orthopedics. 2009;32:401.

41. Alton TB, Gee AO. Classifications in brief: Young and Burgess classification of pelvic ring injuries. Clin Orthop Relat Res. 2014;472:2338-42.

42. Koo H, Leveridge M, Thompson C, Zdero R, Bhandari M, Kreder HJ, et al. Interobserver reliability of the young-burgess and tile classification systems for fractures of the pelvic ring. J Orthop Trauma. 2008;22:379-84.

43. Peng RY, Bongard FS. Hypothermia in trauma patients. J Am Coll Surg. 1999; 188:685-96.

44. Watts DD, Trask A, Soeken K, Perdue P, Dols S, Kaufmann C. Hypothermic coagulopathy in trauma: effect of varying levels of hypothermia on enzyme speed, platelet function, and fibrinolytic activity. J Trauma. 1998:44:846-54.

45. Gentilello LM, Jurkovich GJ, Stark MS, Hassantash SA, O'Keefe GE. Is hypothermia in the victim of major trauma protective or harmful? A randomized, prospective study. Ann Surg. 1997;226:439-47 discussion 447-9.

46. Bilkovski RN, Rivers EP, Horst HM. Targeted resuscitation strategies after injury. Curr Opin Crit Care. 2004;10:529-38.

47. Baron BJ, Scalea TM. Acute blood loss. Emerg Med Clin North Am. 1996;14 $35-55$.

48. American College of Surgeons Committee on Trauma. ATLS • Student Manual. 10th ed. Chicago, IL: American College of Surgeons; 2018.

49. Davis JW, Parks SN, Kaups KL, Gladen HE, O'Donnell-Nicol S. Admission base deficit predicts transfusion requirements and risk of complications. J Trauma. 1996;41:769-74.

50. Wilson M, Davis DP, Coimbra R. Diagnosis and monitoring of hemorrhagic shock during the initial resuscitation of multiple trauma patients: a review. J Emerg Med. 2003;24:413-22.

51. Porter JM, Ivatury RR. In search of the optimal end points of resuscitation in trauma patients: a review. J Trauma. 1998:44:908-14.

52. Abramson D, Scalea TM, Hitchcock R, Trooskin SZ, Henry SM, Greenspan J. Lactate clearance and survival following injury. J Trauma. 1993;35:584-8 discussion 588-9.

53. Lavery RF, Livingston DH, Tortella BJ, Sambol JT, Slomovitz BM, Siegel JH. The utility of venous lactate to triage injured patients in the trauma center. J Am Coll Surg. 2000;190:656-64.

54. Claridge JA, Crabtree TD, Pelletier SJ, Butler K, Sawyer RG, Young JS. Persistent occult hypoperfusion is associated with a significant increase in infection rate and mortality in major trauma patients. J Trauma. 2000;48:814 discussion 14-5.

55. Toth L, King KL, McGrath B, Balogh ZJ. Factors associated with pelvic fracture-related arterial bleeding during trauma resuscitation: a prospective clinical study. J Orthop Trauma. 2014;28:489-95.

56. Odom SR, Howell MD, Silva GS, Nielsen VM, Gupta A, Shapiro NI, et al. Lactate clearance as a predictor of mortality in trauma patients. J Trauma Acute Care Surg. 2013;74:999-1004.

57. Ohmori T, Matsumoto T, Kitamura T, Tamura R, Tada K, Inoue T, et al. Scoring system to predict hemorrhage in pelvic ring fracture. Orthop Traumatol Surg Res. 2016;102:1023-8.

58. Guyette F, Suffoletto B, Castillo JL, Quintero J, Callaway C, Puyana JC Prehospital serum lactate as a predictor of outcomes in trauma patients: a retrospective observational study. J Trauma. 2011:70:782-6.

\section{Ready to submit your research? Choose BMC and benefit from:}

- fast, convenient online submission

- thorough peer review by experienced researchers in your field

- rapid publication on acceptance

- support for research data, including large and complex data types

- gold Open Access which fosters wider collaboration and increased citations

- maximum visibility for your research: over $100 \mathrm{M}$ website views per year

At BMC, research is always in progress.

Learn more biomedcentral.com/submissions 